\title{
PENGELOMPOKAN JUMLAH PENDUDUK SUMATERA BARAT BERDASARKAN ANGKATAN KERJA MENGGUNAKAN ALGORITMA K-MEANS
}

\author{
${ }^{1}$ Devy Safira, ${ }^{2}$ Mustakim, ${ }^{3}$ Ega Dwi Lestari, ${ }^{4}$ Misratul Iffa, ${ }^{5}$ Sella Annisa \\ 1,2,3,4,5 Program Studi Sistem Informasi, Fakultas Sains dan Teknologi UIN Suska Riau \\ Jl. HR Soebrantas KM.18 Panam Pekanbaru - Riau \\ Email: ${ }^{1} 11753202034 @$ students.uin-suska.ac.id, ${ }^{2}$ mustakim@uin-suska.ac.id, \\ 311753200397@ students.uin-suska.ac.id, ${ }^{4} 11753202169 @$ students.uin-suska.ac.id, \\ 511750202124@students.uin-suska.ac.id
}

\begin{abstract}
ABSTRAK
Indonesia adalah suatu negara berkembang yang memiliki banyak permasalahan dalam bidang kesejahteraan rakyat. Saat ini pemerintah Indonesia sedang berusaha menciptakan kesejahteraan dan kemakmuran rakyat dengan cara meningkatkan pembangunan diberbagai bidang. Salah satu cara yang dilakukan pemerintah saat ini adalah meningkatkan ketersediaan lapangan kerja agar dapat mengurangi masalah angkatan kerja. Masalah angkatan kerja, merupakan masalah umum yang sering dihadapi oleh hampir seluruh penduduk didunia bahkan penduduk dinegara maju sekalipun. Umumnya permasalahan angkatan kerja dinegara maju disebabkan oleh ketidakmampuan perusahaan untuk menggaji karyawan yang tinggi, serta meningkatnya jumlah pengangguran yang disebabkan karena perusahaan lebih tertarik menggunakan tenaga kerja robot dibandingkan tenaga kerja manusia. Dalam penelitian ini, dilakukan pengelompokan jumlah penduduk berdasarkan angkatan kerja menggunakan algoritma K-Means. Tujuan dari pengelompokan data ini adalah untuk mendapatkan pengelompokan angkatan kerja pada wilayah Provinsi Sumatera Barat dengan menggunakan algoritma Kmeans, dengan pemodelan tersebut menghasilkan tingkat pengagguran berdasarkan hasil masing-masing cluster yang dihasilkan sehingga dapat memberikan informasi kebutuhan tenaga kerja di Provinsi Sumatera Barat. Hasil dari pengelompokan sepenuhnya memiliki akurasi yang sangat dekat dan baik serta tervalidasi menggunakan data BPS. Selain itu K-Means juga mampu memberikan nilai validitas cluster terbaik berdasarkan DBI dengan nilai 0.238 .
\end{abstract}

Kata kunci: angkatan kerja, k-means, pengelompokan, provinsi sumatera barat.

\section{A. PENDAHULUAN}

Indonesia merupakan salah satu negara berkembang yang memiliki banyak permasalahan dalam bidang kesejahteraan rakyat. Saat ini pemerintah Indonesia sedang berusaha menciptakan kesejahteraan dan kemakmuran rakyat dengan cara meningkatkan pembangunan diberbagai bidang. Pembangunan dalam arti proses, adalah pergerakan dari masyarakat pertanian berbudaya tradisional kearah ekonomi yang berfokus pada rasional, industri, dan jasa [1]. Pembangunan seutuhnya dilaksanakan untuk mewujudkan masyarakat yang sejahtera, adil, makmur, yang merata baik materiil maupun spiritual. Salah satu pembangunan ekonomi yang menjadi titik fokus pemerintah adalah permasalahan dalam bidang pembangunan ekonomi daerah. Menurut Lincolin Arsyad tahun 2010, Pembangunan ekonomi daerah adalah proses pemerintah daerah dan masyarakat untuk mengolah sumber daya yang ada, dan saling bekerja sama antara pemerintah daerah dengan sektor swasta, yang diharapkan mampu menciptakan suatu lapangan kerja baru dan meningkatkan perkembangan kegiatan ekonomi (pertumbuhan ekonomi) dalam wilayah tersebut [2].
Permasalahan pembangunan ekonomi daerah tidak terlepas dari permasalahan ketenagakerjaan. Menurut UU No. 13 tahun 2003, ketenagakerjaan merupakan semua hal yang terkait dengan permasalahan tenaga kerja pada waktu tertentu, baik sebelum, selama, dan sesudah masa kerja. Sedangkan, tenaga kerja merupakan setiap orang yang telah memasuki usia kerja dan mampu melakukan pekerjaan sehingga menghasilkan barang dan/atau jasa untuk memenuhi kebutuhan sendiri maupun untuk kebutuhan masyarakat [3]. Menurut Eddy Cahyono tahun 2017, jika ketenagakerjaan meningkat maka pertumbuhan ekonomi daerah dan pendapatan daerah akan membaik, begitu juga dengan pertumbuhan ekonomi daerah jika pertumbuhan ekonomi daerah meningkat maka ketenagakerjaan juga akan meningkat dan kesejahteraan rakyat juga ikut meningkat. Dalam buku yang berjudul The Principles of Political Economy And Taxation karya David Ricardo, menyatakan bahwa jika suatu upah yang didapatkan penduduk tinggi atau diatas rata-rata, maka jumlah penduduk dan kesejahteraan ekomoni akan meningkat, sebaliknya jika tingkat upah dibawah rata-rata maka, pendapatan ekonomi daerah akan rendah [4]. 
Masalah ketenagakerjaan, merupakan masalah umum dan mendasar yang dihadapi oleh hampir seluruh negara didunia bahkan dinegara maju sekalipun [5]. Umumnya permasalahan ketenagakerjaan di negara maju disebabkan oleh ketidakmampuan perusahaan untuk menggaji karyawan yang tinggi, serta meningkatnya jumlah pengangguran yang disebabkan karena perusahaan lebih tertarik menggunakan tenaga kerja robot dibandingkan tenaga kerja manusia. Sedangkan permasalahan dalam negara berkembang, disebabkan oleh kurangnya kesempatan kerja, upah yang ditawarkan minim serta tingkat produktivitas yang rendah. Masalah ini menjadi kompleks dimana didalamnya terkandung masalah ekonomis, sosial, kesejahteraan dan juga sosial politik [6]. Jumlah penduduk yang tinggi, juga termasuk kedalam permasalahan dibidang angkatan kerja khususnya dalam menciptakan lapangan kerja. Oleh sebab itu diperlukannya lapangan kerja baru untuk dapat menanggulangi jumlah angkatan kerja yang semakin bertambah, serta perlu diadakannya pelatihan kerja untuk dapat meningkatkan produktivitas tenaga kerja [7]. Pelatihan kerja merupakan suatu kegiatan untuk memberi, memperoleh, meningkatkan, serta mengembangkan kompetensi kerja, produktivitas, disiplin, sikap, dan etos kerja sesuai dengan jenjang dan kualifikasi jabatan atau pekerjaan [8].

Salah satu indikator ketenagakerjaan adalah Tingkat Partisipasi Angkatan Kerja (TPAK). TPAK merupakan suatu indikator ketenagakerjaan yang memberikan gambaran tentang penduduk yang aktif secara ekonomi dalam kegiatan sehari-hari yang merujuk pada suatu waktu dalam periode servei. Menurut konsep Badan Pusat Statistik (BPS), penduduk dikelompokkan menjadi dua baguan yaitu penduduk usia kerja dan bukan usia kerja. Penduduk usia kerja yaitu penduduk yang berusia 15 tahun ke atas. Penduduk usia kerja dibedakan menjadi dua kelompok, yaitu angkatan kerja dan bukan angkatan kerja. Angkatan kerja meliputi penduduk berusia 15 tahun ke atas yang sudah mrmpunyai pekerjaan tetapi sementara tidak bekerja,maupun yang sedang aktif mencari pekerjaan. Sedangkan bukan angkatan kerja adalah mereka yang masih sekolah, mengurus rumah tangga, dan lain-lain, termasuk pensiunan dan cacat tubuh [9]. Semakin besar jumlah penduduk yang tergolong bukan angkatan kerja, semakin kecil pula jumlah angkatan kerja, yang mengakibatkan semakin kecil TPAK [10].

Permasalahan dalam angkatan kerja disebabkan oleh kurangnya kebutuhan kompetensi tenaga kerja dimasing-masing daerah, hal ini disebabkan karena tidak adanya pemetaan keahlian tenaga kerja yang dibutuhkan oleh pengguna tenaga kerja. Dalam penelitian ini bertujuan untuk memetakan tingkat angkatan kerja yang bertempat di Provinsi Sumatera barat, agar pemerintah dapat mengetahui daerah mana saja di Sumatera Barat yang diprioritaskan untuk mendapatkan bantuan agar tercapainya program-program pembangunan dari pemerintah [11].

Menurut Faisal Basri tahun 1995, keberhasilan program-program pembangunan angkatan kerja sangat bergantung pada ketetapan pengindentifikasian target gruop dan target area [12]. Dalam Pengidentifikasian ini, dapat mempermudah dalam mengklasifikasikan permasalahan sehingga dapat menjadi tolak ukur dalam membuat keputusan serta menetapkan kebijakan pemerintah yang akan datang. Oleh sebab itu, sangat penting mempertimbangkan pengelompokan dan karakteristik angkatan kerja agar dapat meningkatkan potensi sumber daya kerja

Menurut Kusrini dan Luthfi, pengelompokkan data, dapat diolah dengan menggunakan Data Mining. Data mining adalah teknik statistik, matematika, kecerdasan buatan, dan machine learning untuk mengidentifikasi data yang ada sehingga menghasilkan informasi yang bermanfaat dan berpengetahuan [13]. Data mining dapat dibagi menjadi 6 kelompok yaitu deskripsi, setimasi, prediksi, klasifikasi, clustering (pengelompokan), dan asosiasi. Salah satu dari metode tersebut adalah Clustering. Clustering merupakan suatu metode statistik yang digunakan untuk mengelompokkan sekumpulan objek kedalam kelompok-kelompok berdasarkan karakteristik yang dimilikinya. Teknik clustering yaitu memaksimalkan kesamaan antar anggota satu kelas dan meminimumkan kesamaan antar kelas. Algoritma yang dipakai antara lain algoritma K-Means, Self Organizing Map (SOM) yang diperkenalkan oleh Prof. Teuve Kohonen, dan berbagai algoritma lainnya [14].

Dalam penelitian ini, dilakukan pengelompokan jumlah penduduk menggunakan algoritma K-Means yang mempartisi data menjadi suatu kelompok sehingga data yang memiliki karakteristik yang sama dan karakteristik yang berbeda dengan data yang berada pada kelompok lain (Johnson dan Wichern, 2002). Algoritma KMeans adalah algoritma yang mudah diimplementasikan dan dijalankan, serta relatif cepat, mudah beradaptasi sehingga sering digunakan dalam kehidupan sehari-hari. Algoritma ini dibentuk berdasarkan ide yang sederhana yang ditentukan oleh jumlah cluster yang ingin dibentuk. Data atau elemen pertama dalam cluster dapat dipilih untuk dijadikan sebagai titik pusat (centroid point) cluster. Algoritma K-Means akan melakukan pengulangan langkah-langkah sampai tidak adanya pergeseran cluster lagi dalam data tersebut (tidak ada objek yang dapat dipindahkan) [15].

\section{B. METODOLOGI PENELITIAN}

Metode penelitian ini bertujuan untuk mendapatkan rekomendasi daerah yang memiliki tingkat tenaga kerja rendah sehngga dapat menjadi 
bahan pertimbangan dalam pemberian dana bantuan daerah. Metode penelitian dapat dilihat pada Gambar 1.

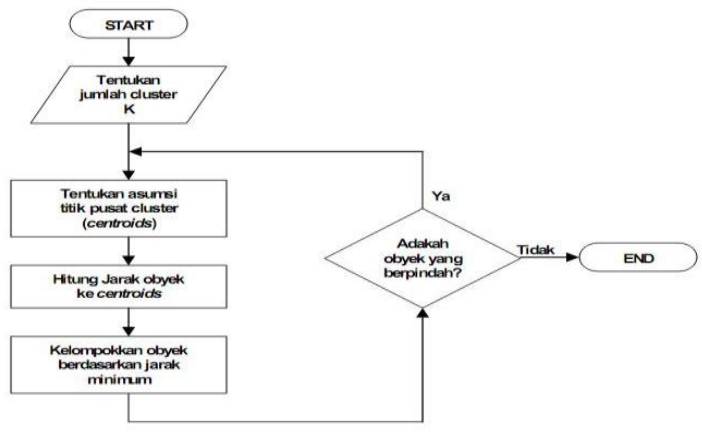

Gambar 1. Metode Penelitian

\section{B.1. Pengumpulan Data}

Berdasarkan sumber data yag digunakan pada penelitian ini, maka metode pengumpulan data yang digunakan adalah: (1) Dokumentasi, adalah metode pengumpulan data dengan mengumpulan catatan-catatan atau dokumen-dokumen. Data yang diperoleh adalah data sekunder yaitu data yang didapatkan dari pihak BPS; (2) Studi Pustaka, adalah mempelajari sumber daru studi karya ilmiah, dan jurnal ilmiah, memiliki hubungan dengan masalah yang akan diteliti.

\section{B.2. Proses K-Means Clustering \\ B.2.1. Preprocessing Data}

Data ketenagakerjaan terlebih dahulu diseleksi dan diambil beberapa atribut dari tabel untuk dianalisis. Terdiri dari 6 atribut data yang masing masing berhubungan dengan karakteristik angkatan kerja dan karakteristik bukan angkatan kerja yaitu Kabupaten/Kota, Bekerja, Pengangguran Terbuka, Bekerja Seminggu Yang Lalu dan Pernah Bekerja, serta Faktor Lainnya. Pengambilan data berdasarkan atribut yang digunakan seperti Tabel 1 dan penyeleksian data menggunakan excel. Adapun tahap yang akan dilakukan adalah:

1. Data Cleaning, yaitu menghilangkan nilai-nilai data yang salah, memperbaiki kekacauan data dan memeriksa data yang tidak konsisten.

2. Data Transformation, yaitu Normalisasi dan pengumpulan data sehingga menjadi sama.

Setelah dilakukannya tahap pre-processing, maka diperoleh hasil yang dapat dilihat pada Tabel 1.

Tabel 1. Normalisasi Data

\begin{tabular}{|c|c|c|c|c|c|}
\hline Kabupaten/Kota & Bekerja & Pengangguran Terbuka & Cari Kerja & Pernah Bekerja & Lainnya \\
\hline 1 & 0,051 & 0,000 & 0,000 & 0,000 & 0,009 \\
\hline 2 & 0,480 & 0,297 & 0,336 & 0,198 & 0,282 \\
\hline 3 & 0,379 & 0,240 & 0,154 & 0,075 & 0,392 \\
\hline 4 & 0,223 & 0,065 & 0,058 & 0,030 & 0,160 \\
\hline$\ldots$. & $\ldots$. & $\ldots$. & $\ldots$. & $\ldots$. & $\ldots$. \\
\hline 17 & 0,099 & 0,093 & 0,049 & 0,101 & 0,035 \\
\hline 18 & 0,111 & 0,040 & 0,041 & 0,043 & 0,014 \\
\hline 19 & 0,043 & 0,036 & 0,017 & 0,091 & 0,083 \\
\hline
\end{tabular}

\section{B.2.2. Tahap Algoritma $K$-Means}

\section{Menentukan Jumlah Cluster}

Data angkatan kerja ini akan dikelompokkan menjadi 3 cluster dimana cluster 0 adalah tingkat pengangguran tinggi, cluster 1 adalah cluster tingkat pengangguran sedang dan cluster 2 cluster tingkat pengangguran rendah.

\section{Menentukan Nilai Centroid}

Pemberian niai centroid yang diambil secara acak data, nilai ini diambil dengan menggunakan rumus random:

c_(j= $(\operatorname{rand}(0,1), \operatorname{rand}(0,1), \operatorname{rand}(0,1)))$

Pada data angkatan kerja ini diambil nilai centroid sebagai berikut:

Data ke 1 sebagai pusat cluster ke 1

Data ke 9 sebagai pusat cluster ke 2
Data ke 13 sebagai pusat cluster 3

Nilai centroid dapat dilihat pada Tabel 2.

\section{Menghitung Jarak Cluster}

Menentukan letak cluster dengan cara membandingkan antara 3 cluster, nilai yang paling kecil (minimum) merupakan nilai yang menjadi pilihan, jika ditemukan nilai yang paling kecil (minimum) maka dapat dimasukkan kedalam cluster tersebut.

\section{Kelompokkan Objek Berdasarkan Jarak Minimum}

Persamaan yang digunakan dalam penentuan jarah dapat diliat pada Persamaan 2:

$$
\operatorname{Min} \sum_{k=1}^{k} d_{i k}=\sqrt{\sum_{j}^{m}(C i j-C k j)^{2}}
$$

Tabel 2. Nilai Centroid Random

\begin{tabular}{|c|c|c|c|c|c|}
\hline Bekerja & Pengangguran Terbuka & Bekerja Seminggu yang Lalu & Cari Kerja & Pernah Bekerja & Lainnya \\
\hline 42200 & 980 & 42200 & 980 & 236 & 1668 \\
\hline 59935 & 4616 & 59935 & 2625 & 1944 & 2533 \\
\hline 201982 & 12556 & 201982 & 12301 & 3584 & 10946 \\
\hline
\end{tabular}


Berdasarkan hasil proses K-Means Clustering diperoleh pengelompokan pada iterasi ke-1 yang ditunjukkan pada Tabel 3.

Tabel 3. Proses iterasi pertama K-Means Clustering

\begin{tabular}{|c|c|c|c|}
\hline Kabupeten/ Kota & Co & C1 & $\mathrm{C} 2$ \\
\hline 1 & & & $*$ \\
\hline 2 & & $*$ & \\
\hline 3 & & * & \\
\hline 4 & & * & \\
\hline$\ldots$ & $\ldots$ & $\ldots$ & $\ldots$ \\
\hline 16 & & & $*$ \\
\hline 17 & & & $*$ \\
\hline 18 & & & $*$ \\
\hline 19 & & & $*$ \\
\hline
\end{tabular}

\section{Hitung Pusat Cluster yang Baru}

Penentuan cluster pada iterasi ke-2 dan seterusnya hingga algoritma berhenti tidak sama seperti pada penentuan centroid awal, sebab iterasi selanjutnya mengambil centroid berdasarkan nilai yang masuk kedalam sebuah cluster dibagi denan jumlah data yang masuk dalam setiap cluster dengan menggunakan Persamaan 3.

$$
C_{k j}=\frac{\sum_{i=1}^{p} x i j}{p}
$$

Pada data angkatan kerja ini nilai dari centroid baru dapat dilihat pada Tabel 4 .

Tabel 4. Centroid Baru Berdasarkan Persamaan 3

\begin{tabular}{cccc}
\hline Bekerja & Pengangguran Terbuka & Cari Kerja & Pernah Bekerja \\
\hline 1,000 & 1,000 & 1,000 & 1,000 \\
0,359 & 0,176 & 0,149 & 0,121 \\
0,049 & 0,032 & 0,017 & 0,045 \\
\hline
\end{tabular}

Proses akhir dari tahap algoritma K-Means ini adalah jika langkah-langkah telah selesai diulang hingga diperoleh hasil data pada suatu cluster yang tepat sama dari data sebelumnya, atau dengan kata lain data tidak berubah lagi posisinya pada cluster.
Jika data tersebut sudah sama dan tidak memiliki pergeseran cluster lagi maka proses untuk pembentukan cluster dapat dihentikan. Berdasarkan data lengkap angkatan kerja diperoleh pembagian wilayah angkatan kerja dapat dilihat pada Tabel 5.

Tabel 5. Proses Iterasi Akhir K-Means Clustering

\begin{tabular}{|c|c|c|c|c|c|c|c|c|c|c|}
\hline Bekerja & $\begin{array}{c}\text { Pengang } \\
\text { guran } \\
\text { Terbuka }\end{array}$ & $\begin{array}{c}\text { Cari } \\
\text { Kerja }\end{array}$ & $\begin{array}{l}\text { Pernah } \\
\text { Bekerja }\end{array}$ & $\begin{array}{c}\text { Lain } \\
\text { nya }\end{array}$ & $\mathrm{CO}$ & C1 & $\mathrm{C2}$ & $\begin{array}{l}\text { Jrk } \\
\text { min }\end{array}$ & $\begin{array}{c}\text { Ite } \\
\text { rasi } \\
1\end{array}$ & $\begin{array}{c}\text { Ite } \\
\text { rasi } \\
2\end{array}$ \\
\hline 0,051 & 0,000 & 0,000 & 0,000 & 0,009 & 2,209 & 0,339 & 0,000 & 0,000 & 2 & 2 \\
\hline 0,480 & 0,297 & 0,336 & 0,198 & 0,282 & 1,538 & 0,370 & 0,706 & 0,370 & 1 & 1 \\
\hline 0,379 & 0,240 & 0,154 & 0,075 & 0,392 & 1,704 & 0,279 & 0,583 & 0,279 & 1 & 1 \\
\hline 0,223 & 0,065 & 0,058 & 0,030 & 0,160 & 2,003 & 0,141 & 0,246 & 0,141 & 1 & 1 \\
\hline 0,384 & 0,146 & 0,111 & 0,123 & 0,305 & 1,776 & 0,205 & 0,496 & 0,205 & 1 & 1 \\
\hline 0,404 & 0,305 & 0,253 & 0,251 & 0,273 & 1,577 & 0,313 & 0,643 & 0,313 & 1 & 1 \\
\hline 0,541 & 0,266 & 0,261 & 0,159 & 0,409 & 1,533 & 0,422 & 0,751 & 0,422 & 1 & 1 \\
\hline 0,452 & 0,111 & 0,077 & 0,125 & 0,398 & 1,752 & 0,327 & 0,587 & 0,327 & 1 & 1 \\
\hline 0,254 & 0,164 & 0,140 & 0,081 & 0,155 & 1,885 & 0,000 & 0,339 & 0,000 & 1 & 1 \\
\hline 0,156 & 0,104 & 0,066 & 0,088 & 0,060 & 2,026 & 0,166 & 0,191 & 0,166 & 1 & 1 \\
\hline 0,238 & 0,092 & 0,044 & 0,079 & 0,115 & 1,987 & 0,127 & 0,251 & 0,127 & 1 & 1 \\
\hline 0,438 & 0,142 & 0,133 & 0,125 & 0,336 & 1,735 & 0,263 & 0,557 & 0,263 & 1 & 1 \\
\hline 1,000 & 1,000 & 1,000 & 1,000 & 1,000 & 0,000 & 1,885 & 2,209 & 0,000 & 0 & 0 \\
\hline 0,018 & 0,023 & 0,001 & 0,021 & 0,021 & 2,199 & 0,341 & 0,047 & 0,047 & 2 & 2 \\
\hline 0,020 & 0,022 & 0,009 & 0,028 & 0,000 & 2,201 & 0,345 & 0,050 & 0,050 & 2 & 2 \\
\hline 0,000 & 0,008 & 0,001 & 0,034 & 0,006 & 2,215 & 0,364 & 0,063 & 0,063 & 2 & 2 \\
\hline 0,099 & 0,093 & 0,049 & 0,101 & 0,035 & 2,068 & 0,228 & 0,156 & 0,156 & 2 & 2 \\
\hline 0,111 & 0,040 & 0,041 & 0,043 & 0,014 & 2,126 & 0,258 & 0,093 & 0,093 & 2 & 2 \\
\hline 0,043 & 0,036 & 0,017 & 0,091 & 0,083 & 2,117 & 0,286 & 0,124 & 0,124 & 2 & 2 \\
\hline
\end{tabular}

\section{ANALISA DAN HASIL}

Analisis data dengan pengelompokan KMeans clustering dilakukan dengan 5 percobaan. Nilai DBI tertinggi dijadikan acuan dalam penentuan cluster terbaik. Berdasarkan percobaan yang dilakukan dapat ditunjukkan pada Gambar 2 terkait dengan hasil percobaan berdasarkan nilai DBI.

Selain itu sebagai validator keakuratan DBI, penelitian ini juga melakukan hitung validitas cluster berdasarkan nilai Silhouette Index (SI) dengan hasil perbandingan dapat ditunjukkan pada Gambar 3.

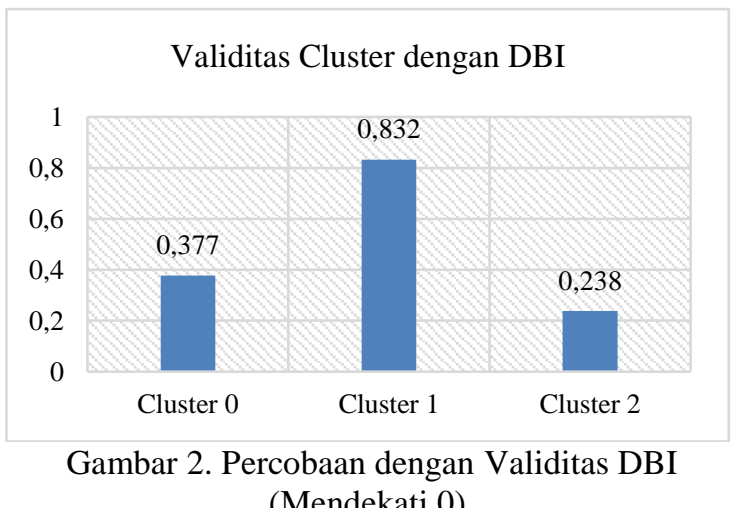

(Mendekati 0) 


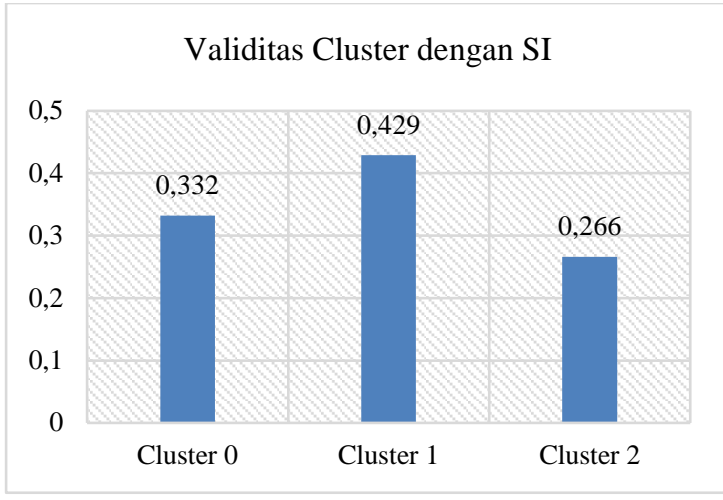

Gambar 3. Percobaan dengan Validitas SI (Mendekati 1)

Sehingga dalam penelitian ini acuan dasar dalam penentuan validitas cluster terbaik menggunakan teknik DBI dengan nilai 0.238. Berdasarkan proses yang telah dilakukan oleh algoritma K-Means, maka diperoleh hasil final yang ditunjukkan pada Tabel 6.

Dari pengelompokan dengan menggunakan metode K-Means menghasilkan 3 (tiga) cluster yang memiliki nilai DBI tertinggi dan mampu mewakili analisa data, yaitu cluster 0 (nol) terdiri dari 1 kota yang ada di Sumatera Barat, yaitu Padang. Cluster 1 (satu) terdiri dari 11 Kabupaten/ Kota, yaitu Pesisir Selatan, Solok, Sijunjung, Tanah Datar, Padang Pariaman, Agam, Lima Puluh Kota, Pasaman, Solok Selatan, Dharmasraya, dan Pasaman Barat. Sedangkan cluster 2 (dua) terdiri dari 7 Kabupaten/ Kota, yaitu Kepulauan Mentawai, Padang, Solok, Sawahlunto, Padang Panjang, Bukittinggi, Payakumbuh dan Pariaman.
Cluster 0 (nol) memiliki anggota sebanyak 1 data, dan masuk kategori tingkat pengangguran tinggi berdasarkan analisis data mining yang dikonfirmasikan kepada pihak BPS. Cluster 1 (satu) memiliki anggota sebanyak 11 data, dan masuk kategori tingkat pengangguran sedang. Serta cluster 2 memiliki anggota sebanyak 7 data, yang masuk ke kategori tingkat pengangguran rendah.

\section{KESIMPULAN}

Pada algoritma K-Means clustering ini dilakukan pengelompokan 19 Kabupaten/ Kota di Provinsi Sumatera Barat berdasarkan indikator angkatan kerja pada tahun 2018 dan dibentuk cluster dengan 3 cluster. Cluster 0 terdiri dari 1 Kota, cluster 1 (satu) terdiri dari 11 Kabupaten/ Kota, dan cluster 2 (dua) terdiri dari 7 Kabupaten/ Kota. Nilai clustering diukur berdasarkan nilai DBI dan SI dengan nilai terbaik diperoleh menggunakan DBI, sehingga analisis data difokuskan berdasarkan validitas cluster terbaik dan dengan jumlah cluster 3. Secara umum kesejahteraan masyarakat Provinsi Sumatera Barat berdasarkan indikator angkatan kerja tahun 2018 dapat dikatakan masih belum merata. Hal ini dilihat dari pengelompoan yang telah dilakukan, cluster 0 memiliki tingkat pengangguran yang tinggi, cluster 1 tingkat pengangguran sedang, dan cluster kedua memiliki tingkat pengangguran yang rendah. Sehingga, hasil pengelompokan dengan algoritma $K$-Means dapat membuktikan dan mengidentifikasi kelompok pengangguran di Kabupaten/ Kota Sumatera Barat. Hal ini diperkuat dan dibuktikan oleh data BPS Nasional.

Tabel 6. Final Data Cluster

\begin{tabular}{|c|c|c|c|c|c|c|c|c|c|}
\hline Kabupaten/Kota & Bekerja & $\begin{array}{l}\text { Pengang } \\
\text { guran }\end{array}$ & $\begin{array}{c}\text { Cari } \\
\text { Kerja }\end{array}$ & $\begin{array}{l}\text { Pernah } \\
\text { Bekerja }\end{array}$ & Lainnya & $\mathrm{CO}$ & C1 & $\mathrm{C} 2$ & Cluster \\
\hline Kepulauan Mentawai & 0,051 & 0 & 0 & 0 & 0 & 2,2 & 0,339 & 0 & 2 \\
\hline Pesisir Selatan & 0,48 & 0,3 & 0,34 & 0,198 & 0,3 & 1,5 & 0,37 & 1 & 1 \\
\hline Solok & 0,379 & 0,24 & 0,15 & 0,075 & 0,4 & 1,7 & 0,279 & 1 & 1 \\
\hline Sijunjung & 0,223 & 0,07 & 0,06 & 0,03 & 0,2 & 2 & 0,141 & 0 & 1 \\
\hline Tanah Datar & 0,384 & 0,15 & 0,11 & 0,123 & 0,3 & 1,8 & 0,205 & 0 & 1 \\
\hline Padang Pariaman & 0,404 & 0,31 & 0,25 & 0,251 & 0,3 & 1,6 & 0,313 & 1 & 1 \\
\hline Agam & 0,541 & 0,27 & 0,26 & 0,159 & 0,4 & 1,5 & 0,422 & 1 & 1 \\
\hline Limapuluh Kota & 0,452 & 0,11 & 0,08 & 0,125 & 0,4 & 1,8 & 0,327 & 1 & 1 \\
\hline Pasaman & 0,254 & 0,16 & 0,14 & 0,081 & 0,2 & 1,9 & 0 & 0 & 1 \\
\hline Solok Selatan & 0,156 & 0,1 & 0,07 & 0,088 & 0,1 & 2 & 0,166 & 0 & 1 \\
\hline Dharmasraya & 0,238 & 0,09 & 0,04 & 0,079 & 0,1 & 2 & 0,127 & 0 & 1 \\
\hline Pasaman Barat & 0,438 & 0,14 & 0,13 & 0,125 & 0,3 & 1,7 & 0,263 & 1 & 1 \\
\hline Padang & 1 & 1 & 1 & 1 & 1 & 0 & 1,885 & 2 & 0 \\
\hline Solok & 0,018 & 0,02 & 0 & 0,021 & 0 & 2,2 & 0,341 & 0 & 2 \\
\hline Sawahlunto & 0,02 & 0,02 & 0,01 & 0,028 & 0 & 2,2 & 0,345 & 0 & 2 \\
\hline Padang Panjang & 0 & 0,01 & 0 & 0,034 & 0 & 2,2 & 0,364 & 0 & 2 \\
\hline Bukittinggi & 0,099 & 0,09 & 0,05 & 0,101 & 0 & 2,1 & 0,228 & 0 & 2 \\
\hline Payakumbuh & 0,111 & 0,04 & 0,04 & 0,043 & 0 & 2,1 & 0,258 & 0 & 2 \\
\hline Pariaman & 0,043 & 0,04 & 0,02 & 0,091 & 0,1 & 2,1 & 0,286 & 0 & 2 \\
\hline
\end{tabular}

\section{REFERENSI}

[1] Triono Ks, Wahyu (2017). Analisis Pertumbuhan Ekonomi, Ketenagakerjaan dan Pengangguran di Kota Medan. Jurnal Social Security.
[2] Arsyad, Lincolin. 2010. Ekonomi Pembangunan. STIE YKPN. Yogyakarta.

[3] Undang-Undang No.13 Tahun 2013 Yang Mengatur Tentang Ketenagakerjaan. 
Lembaran Negara RI Tahun 2003, No.17. Sekretariat Negara. Jakarta

[4] Ricardo, David. 2017. The Principles of Political Economy And Taxation. Inggris: G. Bell.

[5] Karisma, alfi, 2015.MEA 2015Indonesia Masih Mengalami Masalah Ketenagakerjaan. https://www.kompasiana.com/alfi_karisma.di akses pada 14 Agustus 2019.

[6] Sengka, Chrystiwan Adjie. 2015. Analisis Tenaga Kerja Sektoral Di Kota Tomohon. Jurnal Fakultas Peranian UNIVERSITAS SAM RATULANI. Manado.

[7] Hidayat, M.,Sutrisno., \& Hadi,M.F.(2017). Tingkat Partisipasi Angkatan Kerja (TPAK) Perempuan Antar Kabupaten di Provinsi Riau. MediaTren, 12(1), 76-89.

[8] Republik Indonesia. 2013. Undang-Undang No. 13 Tahun 2003 tentang Ketenagakerjaan.

[9] Pius Partanto Dkk, Kamus Ilmiah Popular,. Surabaya, 345.

[10] Simanjuntak, J Payaman. 2001. Pengantar Ekonomi Sumber Daya Manusia. Jakarta:
Lembaga Penerbit Fakultas Ekonomi Universias Indonesia.

[11] Soemartini, Supartini Enny.2017 “Analisis KMeans Cluster Untuk Pengelompokan Kabupaten /Kota Di Jawa Barat Berdasarkan Indikator Masyarakat". Surakarta.

[12] Basri, Faizal dan Haris Munandar (2009) . Lanskap Ekonomi Indonesia, Jakarta.

[13] Kusrini dan Luthfi, E. 2009, Algoritma Data Mining. Andi Offset, Yogyakata.

[14] Lindawati. 2008. "Data Mining Dengan Teknik Clustering Dalam Pengklasifikasian Data Mahasiswa Studi Kasus Prediksi Lama Studimahasiswa Universitas Bina Nusantara". Seminar Nasional Informatika . Yogyakarta.

[15] Kuswantoro, Endik dan Suprapo, Yoyon K. 2015. "Penerapan Algoritma K-Means Dengan Optimasi Jumlah Culster Unutk Pengelompokan Angkatan Kerja Propinsi Jatim". 13:58. Surabaya. 